\title{
Identification of Phycocyanin Isolated from Porphyra tenera and Porphyra yezoensis*1
}

\author{
Haruo MizUno*2, Naomichi Iso*2, Takahide SAITO*2, \\ Fumiaki OHZEKI*2, and Tomoko HATANO*2
}

(Received November 30, 1981)

\begin{abstract}
The solution properties of phycocyanin isolated from two pure Porphyra, i.e. Porphyra tenera and Porphyra yezoensis, were compared with those of phycocyanin from dried laver. All showed similar sedimentation behavior. The sedimentation constant of phycocyanin from Porphyra tenera was 11.5S and that from Porphyra yezoensis was 11.9S. Those values were in good agreement with the value of $11.3 \mathrm{~S}$ reported for phycocyanin from dried laver. Both phycocyanins showed self-association behavior in solution at $\mathrm{pH} \mathrm{5.4,} \mathrm{the} \mathrm{self-association} \mathrm{reaction} \mathrm{system} \mathrm{was}$ assumed to be monomer $\rightarrow$ hexamer. The results showed that the phycocyanins investigated in this work were the same.
\end{abstract}

Phycocyanin which is found in abundance in blue-green and red algae, is a chromoprotein, its function being to harvest the light energy during photosythesis. The properties of this protein isolated from various algae have been extensively studied by many investigators in various fields of science. The initial study of the molecular weight of phycocyanin was performed by SVEDBERg and his co-worker. ${ }^{1)} \quad$ After that, the physico-chemical studies of phycocyanin have been done by different experimental techniques. And several characteristics of phycocyanin, such as absorption and fluorescence spectra, aggregation properties, sedimentation behavior, molecular weight and molecular shape, amino acid composition, subunit and their structure, have already been reported. ${ }^{2-7}$ )

In the previous research, we studied the solution properties of phycocyanin by means of sedimentation transportation and equilibrium, ${ }^{8-10)}$ osmotic pressure, ${ }^{11}$ and by viscosity ${ }^{11)}$ measurements. It was reported from the sedimentation transportation and equilibrium measurements that the mode of self-association reaction was precisely a mono-

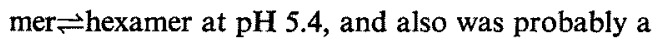
monomer $\rightleftharpoons$ trimer $\rightleftharpoons$ tetramer at $\mathrm{pH}$ 6.8. These self-association reactions were spontaneous in both the solutions of $\mathrm{pH} 5.4$ and of $\mathrm{pH}$ 6.8. Large values of equilibrium constant were estimated for the self-association reaction, and it was assumed that the self-association equilibrium of phycocyanin inclines toward a one-side extreme. The value of $2.56 \times 10^{5}$ as the molecular weight of phycocyanin was obtained from the osmotic pressure

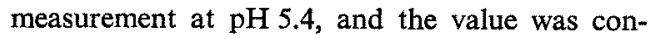
sidered to be the molecular weight of hexamer of phycocyanin. Moreover, it was reported from the electron microscopic observation of phycocyanin that the phycocyanin aggregate was homogeneous and stable at $\mathrm{pH} 4.0 \sim 5.6$, and the aggregate decomposed to various small molecular species at higher $\mathrm{pH}$ region, 6.0 10.0.12) The structure of higher aggregate, formed by many small particles, was a ring structure having a central hole. The dimension of the ring-shaped aggregate was not consistent with that estimated from the intrinsic viscosity and sedimentation constant.

The phycoyanin used in our previous studies was isolated from dried laver. We had been thinking that the laver was made from Porphyra tenera, which is a kind of red alga. It has been pointed out by a phycologist that the raw material of the dried laver contains some different species of red algae, and that the phycocyanin from the laver might be a mixture of that from a few kinds of red algae. Since the several different absorption spectra, sedimentation pattern and molecular weight were proposed for phycocyanin obtained from different algal sources, it is necessary to investigate the properties of phycocyanin isolated from pure species of red alga which existed in the dried laver.

The purpose of the work reported here was to

\footnotetext{
*1 Presented at the Annual Meeting of Japan. Soc. Sci. Fish., Tokyo, April 1980.

*2 Tokyo University of Fisheries, Konan-4, Minato, Tokyo 108, Japan (水野治夫 - 磯直道・紊藤隆英・ 大関文照 - 烟野友子：東京水産大学).
} 
investigate the sedimentation behavior of phycocyanin isolated from two different pure algal sources. Most of our investigations concerning to the solution properties of phycocyanin had relied on sedimentation measurements, and the results were effective to interprete in the molecular property of phycocyanin.

Electron microscopic observation and viscosity investigation cannot be used for the determination of the characteristics of phycocyanin. It was thought advisable to investigate the sedimentation behavior in order to understand the molecular properties of phycocyanin obtained from different algae. For the isolation of phycocyanin, dried laver which was made from Porphyra tenera and Porphyra yezoensis were chosen as the sources.

\section{Experimentals}

\section{Preparation of Phycocyanin}

The crystalline phycocyanin used in this study was isolated from dried Porphyra tenera and Porphyra yezoensis by repeating the precipitation with ammonium sulfate. The details of both the preparation and the purification have been described previously. ${ }^{8)}$ The purity of crystallized phycocyanin was ascertained from the measurements of the absorbance at $620 \mathrm{~nm}$ and at $280 \mathrm{~nm}$ in a phosphate buffer solution. The ratio of absorbance at $620 \mathrm{~nm}$ to that at $280 \mathrm{~nm}$ has usually been used as a criterion for judging the purity of phycocyanin; when the ratio is greater than 4.0 , the protein is considered to have a high purity. ${ }^{13)}$ The value of the ratio measured was greater than 4.2 for the phycocyanin obtained in this work. Therefore, the phycocyanin used in this study was a highly purified sample. Prior to use, the crystalline phycocyanin was dissolved in water and dialyzed against an acetate buffer solution at $5^{\circ} \mathrm{C}$, and then centrifuged to remove any insoluble substances. The $\mathrm{pH}$ and ionic strength of the acetate buffer solution used as solvent were limited to 5.4 and 0.1 , respectively, because the phycocyanin is most stable in this condition, a fact which was confirmed from the osmotic pressure measurement and the electron microscopic observation, which we previously carried out. ${ }^{11,12)}$

\section{Sedimentation Velocity Measurements}

The sedimentation velocity measurements were performed at $25^{\circ} \mathrm{C}$ and $51200 \mathrm{rpm}$ on a Hitachi Model UCA-1 ultracentrifuge with a schlieren optical system. Sedimentation coefficients were calculated from the movement of the peak in the schlieren pattern, and the sedimentation constant, $\mathrm{s}^{0}$, was obtained from the plot of sedimentation coefficient against concentration.

\section{Sedimentation Equilibrium Measurements}

The sedimentation equilibrium measurements were performed at $25^{\circ} \mathrm{C}$ on the same ultracentrifuge in the cases of the sedimentation velocity measurements, although an interference optical system was used. The rotor speeds were set at approximately $8000 \sim 9000 \mathrm{rpm}$. All runs were made at a given speed for approximately $24 \mathrm{~h}$ so as to ensure that an equilibrium was established in about a 2-mm liquid column. The apparent weightaverage molecular weights at several radial positions in the column were evaluated by a method previously reported elsewhere. ${ }^{14)}$ The value of $0.746 \mathrm{~m} / / \mathrm{g}^{15)}$ was used for the partial specific volume of phycocyanin in all the evaluations.

\section{Results and Discussion}

The absorption spectra of phycocyanin isolated from Porphyra tenera and Porphyra yezoensis were identical, and exhibited a characteristic peak at $620 \mathrm{~nm}$ as shown in Fig. 1. The absorption spectrum agrees closely with that observed for phycocyanin obtained from dried laver. ${ }^{8)}$

The sedimentation patterns of phycocyanin from two species showed a single peak, the same as that pattern of phycocyanin from dried laver. The sedimentation constants of phycocyanin in acetate buffer solution are listed in Table 1. As shown in Table 1, the values of the sedimentation constant of phycocyanin from Porphyra tenera and Porphyra yezoensis are almost of the same value. These values are in good agreement with the value of $11.3 \mathrm{~S}$ reported previously for phycocyanin from dried laver. ${ }^{8)}$

KURATA and FuJITA reported the relationship between molecular weight and sedimentation

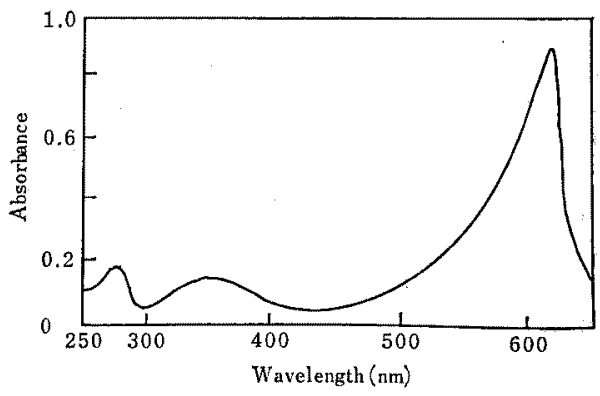

Fig. 1. Absorption spectrum of phycocyanin in phosphate buffer solution at $\mathrm{pH} 6.8$. 
Table 1. Sedimentation constant of phycocyanin from various algae in acetate buffer solution $(\mathrm{pH}$ 5.4)

\begin{tabular}{cc}
\hline \multicolumn{1}{c}{ Alga } & $\begin{array}{c}\text { Sedimentation } \\
\text { constant (S) }\end{array}$ \\
\hline Porphyra tenera & 11.5 \\
Porphyra yezoensis & 11.9 \\
Dried laver $^{8}$ & 11.3 \\
\hline
\end{tabular}

constant for the globular proteins using the data by TANFORD. ${ }^{10)}$ They showed that the plot of the logarithm of molecular weight versus the logarithm of sedimentation constant will give a straight line, having a slope of $2 / 3$. Since the phycocyanin is assumed to be a globular protein, the value of sedimentation constant of $11.3 \mathrm{~S}$, obtained earlier for phycocyanin from dried laver, corresponds to the molecular weight of $2.45 \times 10^{5}$, which was calculated from the above described relationship. The value is in agreement with that of $2.56 \times 10^{5}$ which was previously obtained from the osmotic pressure measurement at $\mathrm{pH}$ 5.4.11) The sedimentation constant of $11.5 \mathrm{~S}$ (Porphyra tenera) and that of 11.9S (Porphyra yezoensis) obtained in this study corresponds to the molecular weight of $2.51 \times 10^{5}$ and to that of $2.65 \times 10^{5}$, respectively. These values are in agreement with the molecular weight of $2.56 \times 10^{5}$.

Figure 2 shows the plots of the apparent weightaverage molecular weight versus concentration of of phycocyanin in the solution column of the ultracentrifuge cell for the sedimentation equilibrium measurements. As shown in this figure, the apparent weight-average molecular weights increase with an increase in the solute concentration in the low concentration region, and the apparent weight-average molecular weights reach a saturated value in the higher concentration region. This behavior represents the characteristic

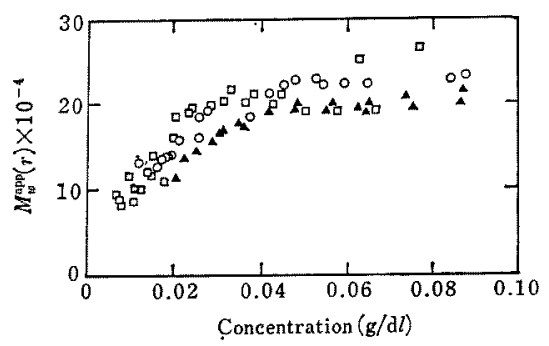

Fig. 2. Plots of the apparent weight-average molecular weight versus concentration of phycocyanin, $\square$; Porphyra tenera, А; Porphyra yezoensis, $O$; dried laver. ${ }^{18)}$ of a self-association reaction system. It is clear from the plots that the phycocyanin samples from the two kinds of algae, Porphyra tenera and Porphyra yezoensis, undergo a self-association reaction in solution.

ADAMS and WILLIAMs have proposed a method for evaluating the equilibrium constant of association-dissociation system from the sedimentation equilibrium measurement. ${ }^{17)}$ In the previous study, ${ }^{18)}$ the equilibrium constant of phycocyanin at pH 5.4 and ionic strength 0.1 and the temperature at $25^{\circ} \mathrm{C}$ was estimated by using their method. In this estimation, the non-ideal parameter, $B,{ }^{17}$ ) was neglected, because the phycocyanin solution was considered to be a pseudo-ideal solution. ${ }^{11)}$ And the value of $2 \times 10^{11}(\mathrm{dl} / \mathrm{g})^{5}$ was obtained as the equilibrium constant for monomer $\rightleftharpoons$ hexamer equilibrium system on the basis of concentration dependence of the weight-average molecular weight in the ultracentrifuge cell represented by open circles in Fig. 2.

As shown in Fig. 2, the experimental values of apparent weight-average molecular weight in this study are consistent with those obtained in the previous study within experimental error in the whole concentration region. It can be said that the self-association behavior of phycocyanins from two kinds of algae is the same as that of phycocyanin from dried laver.

On the basis of the presented results, it is considered that the phycocyanins from Porphyra tenera and Porphyra yezoensis have similar properties, molecular weight, dissociation-association behavior and hydrodynamic behavior in solution.

\section{Acknowledgement}

The authors wish to express their gratitude to Dr. T. OoHusA of Yamamoto Nori Research Laboratory for supplying sample.

\section{References}

1) T. Svedberg and T. Katsural: J. Am. Chem. Soc., 51, 3573-3583 (1929).

2) D. S. Berns, H. L. CRespi, and J. J. Katz: $J$. Am. Chem. Soc., 85, 8-14 (1963).

3) A. Hattori, H. L. Crespi, and J. J. Katz: Biochemistry, 41, 1225-1238 (1965).

4) A. Hattori and Y. FujItA: J. Biochem., 46, 633644 (1959).

5) M. Kato, W. I. Lee, B. E. Eichinger, and J. M. SCHURR: Biopolymers, 13, 2293-2304 (1974).

6) R. MACColl, W. HABig, and D.S. Berns: $J$. 
Biol. Chem., 248, 7080-7086 (1973).

7) D. S. Berns and M. R. EDWARds: Arch. Biochem. Biophys., 110, 511-516 (1965).

8) T. SAIto, N. Iso, and H. Mizuno: Bull. Chem. Soc. Jpn., 47, 1375-1379 (1974).

9) H. Mizuno, T. Sarto, and N. Iso: Bull. Chem. Soc. Jpn., 48, 3496-3499 (1975).

10) N. Iso, H. Mizuno, T. Satto, N. NitTa, and K. YoshiZAKI: Bull. Chem. Soc. Jpn., 50, 28922895 (1977).

11) A. Kotera, T. SAito, N. Iso, H. Mizuno, and N. TAKI: Bull. Chem. Soc. Jpn., 48, 1176-1179 (1975).

12) H. Mizuno, T. Saito, N. Iso, K. Hirate, and I. Kitamura: J. Tokyo Univ. Fish., 63, 1-8 (1976).
13) R. MACColl, J. J. LeE, and D. S. Berns: Biochem. J., 122, 421-426 (1971).

14) J. W. Williams: Ultracentrifugation of Macromolecules, Academic Press, New York and London, 1972, pp. 79-89.

15) T. Saito, N. Iso, H. Mizuno, F. Ozeki, and Y. MAtsu: Bull. Chem. Soc. Jpn., 53, 599-602 (1980).

16) M. Kurata and H. Funta: in "Biopolymer" (ed. by Biophysical Society of Japan) II, Yoshioka, Kyoto, 1966, pp. 312-318.

17) E. T. Adams, JR. and J. W. Willams: J. Am. Chem. Soc., 86, 3454-3461 (1964).

18) T. SaIto, N. Iso, H. Mizuno, and I. Kitamura: Bull. Chem. Soc. Jpn., 51, 3471-3474 (1978). 